Vol.15, No. 56, July, 2020, 743-752

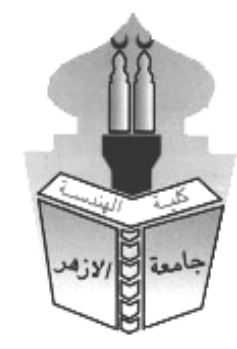

\title{
NON-LINEAR FINITE ELEMENT MODEL FOR REINFORCED CONCRETE DEEP BEAMS FAILING IN SHEAR
}

\author{
Ahmed Abdel Hafiz Mahmoud \\ Civil Engineering Department, Faculty of Engineering, Al-Azhar University .Cairo, Egypt. \\ Email: ahmed.hafiz@azhar.edu.eg
}

\begin{abstract}
Six reinforced concrete deep beams, previously tested, are analyzed using 3D nonlinear finite element methods. These beams were tested under a vertical monotonically increasing load till failure. Two beams specimens were having flexure reinforcement only, two were with shear reinforcement, and two with shear and side reinforcement. All specimens are analyzed using the concrete damaged plasticity model offered in ABAQUS software. Damage can be introduced in this model and it is defined separately in compression and tension. The model is also provided with viscosity parameter that provides additional ductility in the structure and helps to overcome convergence problems. The effect of mesh size, dilation angle, and viscosity parameters are also studied. All numerical results are compared to the test results in terms of load-deflection responses, failure mode, and crack patterns. Finite element analysis results are in good agreement with the experimental results and can give an insight into the failure mechanisms and crack developments of each beam. The predictive ability of the calibrated models confirms their ability for parametric studies examining the shear behavior of reinforced concrete deep beams with and without shear reinforcement.
\end{abstract}

\section{KEYWORDS: Concrete Damaged Plasticity, Shear Failure, Deep Beams, Non-linear Analysis, and Finite elements.}

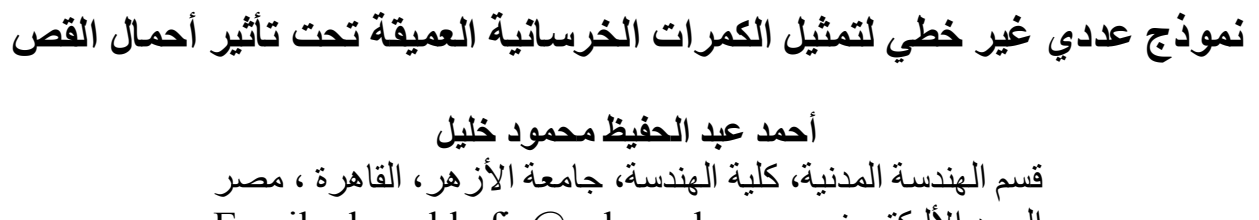

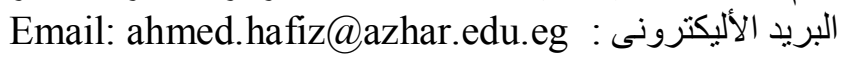

في هذا البحث، نم عمل نموذج عددي غير خطي باستخدام طريقة العناصر المحددة لتمثيل الكمرات الخرسانية العميقة التي

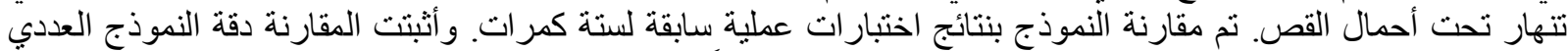

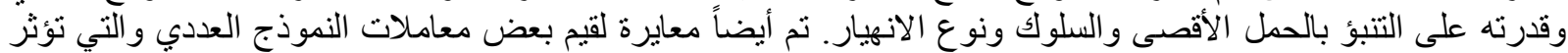

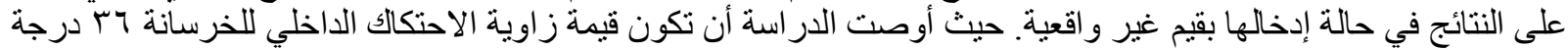

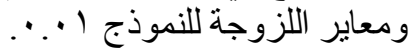

الكلمات المفتاحية: نموذج الانهيار اللان، انهيار القص، الكمرات العميقة، التحليل الغير خطي، و العناصر المحددة. 


\section{INTRODUCTION}

Finite element analysis of reinforced concrete deep beams can give a perception of the beam behavior, predict possible failure modes, support experimental results, and extend these results where test measurements are absent. The concrete damaged plasticity model (CDP) is one of the famous concrete nonlinear material models. Recent researches indicated the ability of (CDP) model to describe the complex behavior of concrete under the triaxial state. Therefore, it can predict the crack location, and propagation of shear cracks leading to shear failure. However, to obtain realistic results, some model parameters must be calibrated against experimental results. Previous researches indicated model sensitivity to such parameters(Michał \& Andrzej, 2015). In this paper, six reinforced concrete deep beams are analyzed using the ABAQUS finite element analys is software with the concrete damaged plasticity model. The analyzed beams have the same configuration of beams tested earlier by(Teng et al., 1998). The effect of some (CDP) model parameters is studied, and the behavior of the analyzed beams is compared with experimental observations.

\section{NON-LINEAR FINITE ELEMENT MODEL.}

In this study, the non-linear finite element software ABAQUS is employed. A summary of the concrete modeling is given, and all the assumptions of modeling are listed below.

\subsection{Concrete damaged plasticity model (CDP)}

The concrete damaged plasticity model (CDP) used in ABAQUS software is implemented to represent the inelastic mechanical behavior of concrete. This model is a modification of the Drucker-Prager failure criteria(Śledziewski, 2017). Modifications have been done on by (Lubliner et al., 1989), and by (Lee \& Fenves, 1998). The main parameters and features of the (CDP) model are presented as follows.

\subsubsection{Concrete Failure modes}

The concrete damaged plasticity model considers both the tensile cracking and the compressive crushing of concrete as possible failure modes (Hibbitt et al., 2012). As shown in figure (1), under uniaxial tension the stress-strain response follows a linear elastic relationship until reaching the value of failure stress, $\sigma_{t 0}$. Beyond $\sigma_{t 0}$, strain-softening behavior for cracked concrete is defined. Hence, the post failure stress is a function of cracking strain, $\varepsilon_{t}^{\sim e k}$.The cracking strain is defined as the total strain minus the elastic strain corresponding to the undamaged material, $\varepsilon_{t}^{\sim c k}=\varepsilon_{t}-\varepsilon_{0 t}^{\sim \theta l}$, where $\varepsilon_{0 t}^{\sim \theta l}=\sigma_{t} / E_{0}$

Under uniaxial compression, the response is linear until the value of the initial yield, $\sigma_{\mathrm{c} 0}$. In the plastic regime, the response is typically characterized by stress hardening followed by strainsoftening beyond the ultimate stress $\sigma_{\mathrm{cu}}$. This representation is simplified, but captures the main features of the concrete response (Hibbitt et al., 2012)

The uniaxial stress-strain curves are converted into stress versus plastic strain curves. The stressstrain data for concrete used in the current study is based on the model of (Carreira \& Chu, 1985). However, this conversion from elastic to plastic strain is performed automatically by ABAQUS from user-provided stress-strain data, as explained below (Hibbitt et al., 2012). Thus,

$\sigma_{t}=\sigma_{t}\left(\varepsilon_{t}^{\sim p l}, \varepsilon_{t}^{\sim * p l}, \theta, f_{i}\right)$

$\sigma_{\sigma}=\sigma_{c}\left(\varepsilon_{\sigma}^{\alpha} p l, \varepsilon_{\sigma}^{\alpha} p l, \theta, f_{i}\right)$

Where, the subscripts $\mathrm{t}$ and $\mathrm{c}$ refer to tension and compression, respectively, $\varepsilon_{t}{ }^{p l}$ and $\varepsilon_{\varepsilon}{ }^{p l}$ are the equivalent plastic strains, $\varepsilon_{t}^{\sim * p l}$, and $\varepsilon_{c}^{\alpha * p l}$, are the equivalent plastic strain rates, $\theta$ is the temperature, and $f_{i}$ are any other predefined field variables. 

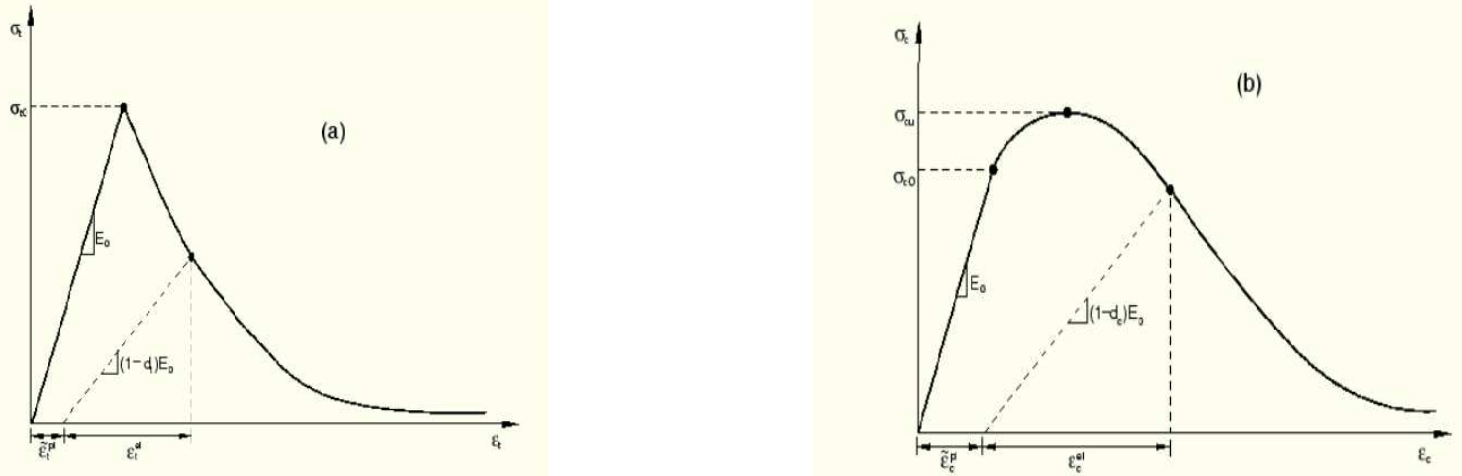

Figure (1), Response of concrete to uniaxial loading in tension (a) and compression (b) (Hibbitt et al., 2012)

\subsubsection{Strength degradation}

As shown in figure (1), when the concrete specimen is unloaded from any point on the strainsoftening branch of the stress-strain curves, the unloading response is weakened, the elastic stiffness of the material appears to be damaged (or degraded). The degradation of the elastic stiffness is characterized by two damage variables, $d_{c}$ and, $d_{t}$, which are assumed to be functions of the plastic strains, temperature, and field variables as follows (Hibbitt et al., 2012).

$d_{t}=d_{t}\left(\varepsilon_{t}^{\alpha p l}, \theta, f_{i}\right), 0 \leq d_{t} \leq 1$

$d_{c}=d_{c}\left(\varepsilon_{c}{ }^{*}{ }^{p l}, \theta, f_{i}\right), 0 \leq d_{c} \leq 1$

The damage variables can take values from zero, representing the undamaged material, to one, which represents the total loss of strength.

If $E_{0}$ is the initial (undamaged) elastic stiffness of the material, the stress-strain relations under uniaxial tension and compression loading are, respectively:

$$
\begin{aligned}
& \sigma_{t}=\left(1-d_{t}\right) E_{0}\left(\varepsilon_{t}-\varepsilon_{t}^{\alpha p}\right) \\
& \sigma_{c}=\left(1-d_{c}\right) E_{0}\left(\varepsilon_{c}-\varepsilon_{c}^{\alpha p l}\right)
\end{aligned}
$$

In addition, the effective tensile and compressive cohesion stresses to determine the size of the failure (yield) surface and are defined as follows.

$$
\begin{aligned}
& \tilde{\sigma}_{t}=\frac{\sigma_{t}}{\left(1-d_{t}\right)}=E_{0}\left(\varepsilon_{t}-\varepsilon_{t}^{*} p l\right) \\
& \tilde{\sigma}=\frac{\sigma_{v}}{\left(1-d_{c}\right)}=E_{0}\left(\varepsilon_{c}-\varepsilon_{c}^{*} p h\right)
\end{aligned}
$$

\subsubsection{Failure surface in CDP model}

According to (Lubliner et al., 1989) and (Lee \& Fenves, 1998), the failure surface in (CDP) model in the deviatoric cross-section does not need to be a circle and is regulated by parameter $\mathrm{K}_{\mathrm{c}}$. The physical interpretation of parameter $\mathrm{K}_{\mathrm{c}}$ is the ratio of the distances from the hydrostatic axis to the compression and tension meridians in the deviatoric cross-section as shown in figure 2. This ratio lays between 0.5 and 1 . If $K_{c}=1$, the deviatoric cross-section of the failure surface becomes a circle, as is the case in the classic Drucker-Prager theory. In this study, the value of $\mathrm{K}_{\mathrm{c}}$ was taken 0.667 in accordance with ABAQUS theory manual (Hibbitt et al., 2012). 


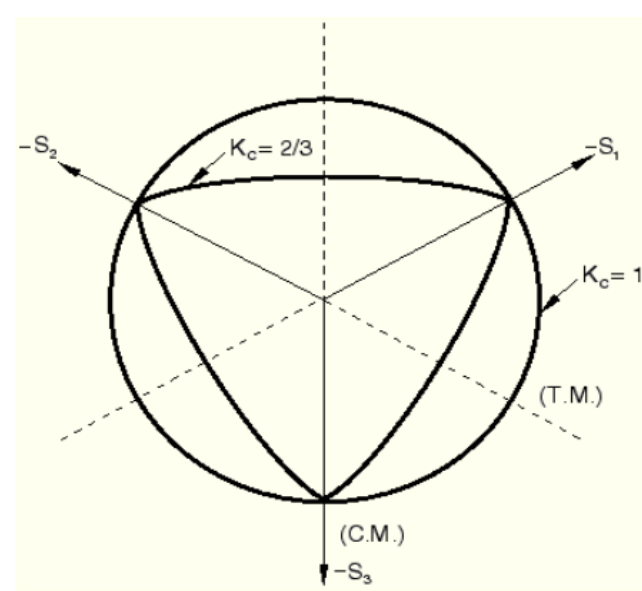

Figure (2), Yield surface in plane stress according to CDP model. (Hibbitt et al., 2012)

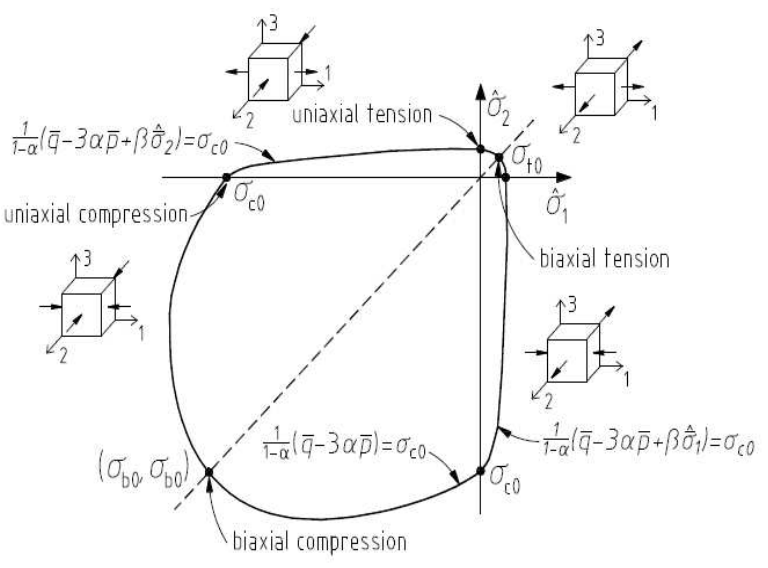

Figure (3), Strength of concrete under bi-axial stresses in CDP model. (Śledziewski, 2017)

In addition, another parameter is $\sigma_{\mathrm{b} 0} / \sigma_{\mathrm{c} 0}$ which describes the behavior of concrete under biaxial compression as shown in figure 3 . The value of $\sigma_{\mathrm{b} 0} / \sigma_{\mathrm{c} 0}$ determines the ratio of concrete strength in a biaxial state to the strength in the uniaxial state. The value of this parameter is taken 1.16 in the current study based on the recommendations of ABAQUS theory manual (Hibbitt et al., 2012).

Moreover, the parameter describing the behavior of concrete in a complex stress state is the dilation angle $(\psi)$, that is the angle of the inclination of the asymptote of the failure surface in relation to the hydrostatic axis, measured in the meridian plane (the angle of internal friction in the concrete) (Hibbitt et al., 2012). Some researchers recommend the value of $\psi$ between $36^{\circ}$ and $45^{\circ}$. Other researchers suggested lower values of dilation angle based on concrete confinement levels(Michał \& Andrzej, 2015). Therefore, in the current study, different values of $\psi$ are calibrated against experimental results to identify the best angle representing experimental results as described later.

Furthermore, to overcome some of the convergence difficulties, the ABAQUS CDP model adopts an optional viscosity parameter. Previous researchers (Michał \& Andrzej, 2015) indicated that the viscosity parameter affects crack localization. Therefore, it must be chosen with great care. The viscosity parameter is between 0 and 0.01 . When applying higher values of the viscosity parameter, the damage zone spreads to many finite elements leading to diffuse and smeared cracking patterns. On the other hand, lower values of viscosity parameter localize cracks location and may lead to conversion problems. Shear failure is affected by cracks localization and propagation. Therefore, different values of viscosity parameters are examined in the current study to choose the best value matching experimental behavior.

\subsection{Modeling methodology}

The whole beam is modeled in ABAQUS. Concrete is modeled with 3D 8-noded elements (C3D8), flexural, transverse, and side reinforcement is modeled with 3D 2-noded linear truss elements (T3D2). A perfect bond is assumed between concrete and reinforcement through the embedded method in ABAQUS. The mesh size is taken equal to $25 \mathrm{~mm}$ based on a calibration analysis discussed later. Tie constraints are adopted to model the interaction between the tested beam, supporting, and loading plates. Tie constraints tie two separate surfaces together to avoid relative motion between them (Hibbitt et al., 2012). Force controlled static analysis is conducted in ABAQUS/Standard (Abaqus, 2014). The modified Riks algorithm type of analysis is used in the current analyses. Simple supports are introduced along the edges of the beams at the bottom as shown in figure (4). 


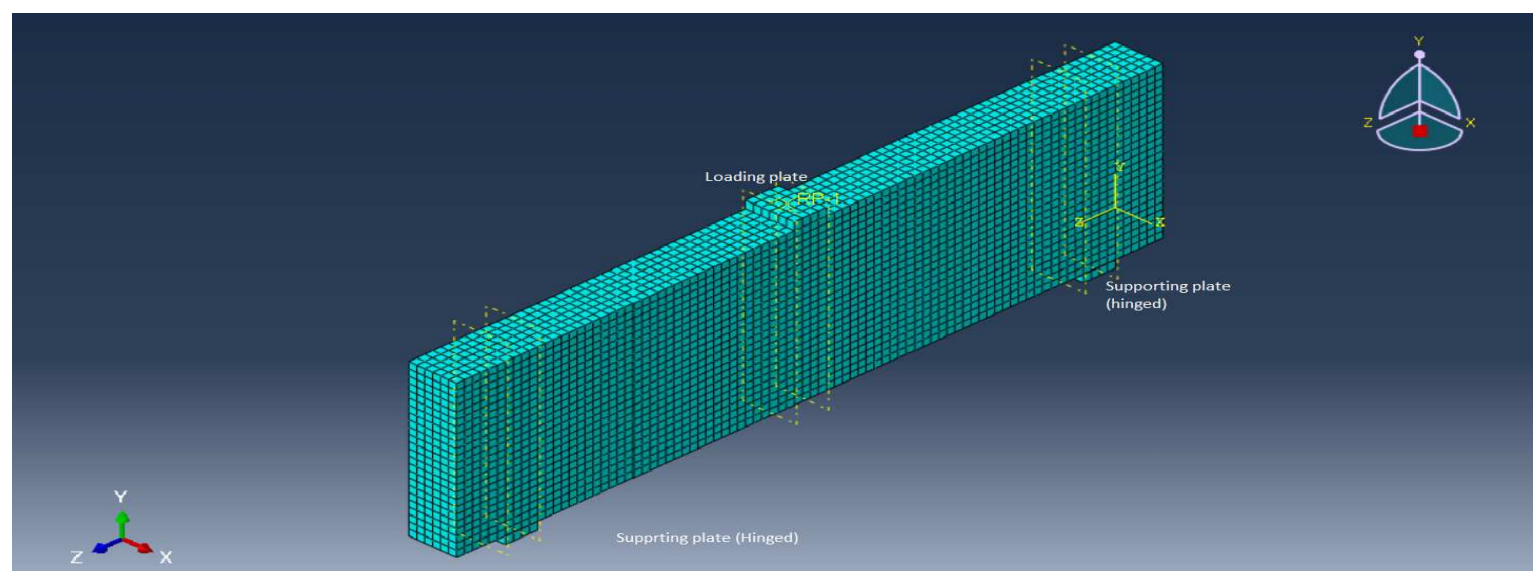

Figure (4), Finite element model

\section{VERIFICATION OF THE FINITE ELEMENT MODEL}

To verify the proposed finite element model, analyses results are compared against experimental test results of six reinforced concrete deep beams tested by (Teng et al., 1998). The beams in comparison have a variable amount of flexural, transverse, and side reinforcement. Figure (5) shows all beams setup and details. Besides, table (1) shows the mechanical properties of the beams.

Table (1), mechanical properties of beams of the verification study

\begin{tabular}{|c|c|c|c|c|c|c|c|c|c|c|c|c|c|c|}
\hline \multirow[t]{2}{*}{ No } & \multirow[t]{2}{*}{$\begin{array}{l}\text { Beam } \\
\text { ID }\end{array}$} & \multirow[t]{2}{*}{$\begin{array}{c}\mathrm{f}_{\mathrm{c}} \\
\mathrm{Mpa}\end{array}$} & \multicolumn{3}{|c|}{ Steel strength } & \multicolumn{3}{|c|}{$\begin{array}{l}\text { Main tension } \\
\text { reinforcement }\end{array}$} & \multicolumn{3}{|c|}{$\begin{array}{l}\text { Vertical web } \\
\text { reinforcement }\end{array}$} & \multicolumn{3}{|c|}{$\begin{array}{c}\text { Horizontal web } \\
\text { reinforcement }\end{array}$} \\
\hline & & & $f_{y m}$ & $f_{y v}$ & $\mathrm{f}_{\mathrm{yh}}$ & $\begin{array}{c}\mathrm{A}_{\mathrm{s}} \\
\mathrm{mm}^{2}\end{array}$ & $\begin{array}{l}\mathrm{A}_{\mathrm{s}, \mathrm{top}} \\
\mathrm{mm}^{2}\end{array}$ & $\mathrm{Y}(\mathrm{As})$ & $\begin{array}{l}\mathrm{A}_{\mathrm{v}} \\
\mathrm{mm}^{2}\end{array}$ & No & $\begin{array}{c}\mathrm{S}_{\mathrm{v}} \\
\mathrm{mm}\end{array}$ & $\begin{array}{l}\mathrm{A}_{\mathrm{h}} \\
\mathrm{mm}^{2}\end{array}$ & No & $\begin{array}{l}\mathrm{s}_{\mathrm{h}} \\
\mathrm{mm}\end{array}$ \\
\hline 1 & N-1a & 38.21 & 754 & - & - & 1520 & 760 & 525 & - & - & - & - & - & - \\
\hline 2 & $\mathrm{~N}-1 \mathrm{~b}$ & 38.65 & 754 & - & - & 760 & 760 & 550 & - & - & - & - & - & - \\
\hline 3 & $\mathrm{~N}-2 \mathrm{a}$ & 38.21 & 754 & 532 & - & 1520 & 760 & 525 & 157 & 5 & 150 & - & - & - \\
\hline 4 & $\mathrm{~N}-2 \mathrm{~b}$ & 38.60 & 754 & 532 & - & 760 & 760 & 550 & 157 & 5 & 150 & - & - & - \\
\hline 5 & $\mathrm{~N}-3 \mathrm{a}$ & 38.22 & 754 & 406 & 532 & 1520 & 760 & 525 & 157 & 5 & 150 & 157 & 4 & 90 \\
\hline 6 & $\mathrm{~N}-3 b$ & 38.58 & 754 & 406 & 532 & 760 & 760 & 550 & 157 & 5 & 150 & 157 & 4 & 90 \\
\hline
\end{tabular}

Moreover, in order to obtain proper and realistic results, mesh size, as well as, some CDP model parameters are calibrated as follows.

\subsection{Effect of mesh size}

To calibrate the effect of mesh size, multiple analyses using three different mesh sizes are conducted. The mesh sizes are 25,50, and $75 \mathrm{~mm}$. Figure (6) shows the load-deflection curve for beam N-3b using different mesh sizes in comparison with the experimental curve. The comparison shows identical initial stiffness for the three FEM beams, but the post cracking behavior is significantly different. This is because of the variation of crack location due to different mesh sizes. Also, the most accurate response compared to experimental behavior is for the beam with a $25 \mathrm{~mm}$ mesh size. However, decreasing mesh size less than $25 \mathrm{~mm}$ shows increased analysis cost, but with no sound accuracy enhancement. Therefore, mesh size is taken $25 \mathrm{~mm}$ in all subsequent analyses due to better accuracy with reasonable analysis cost. 

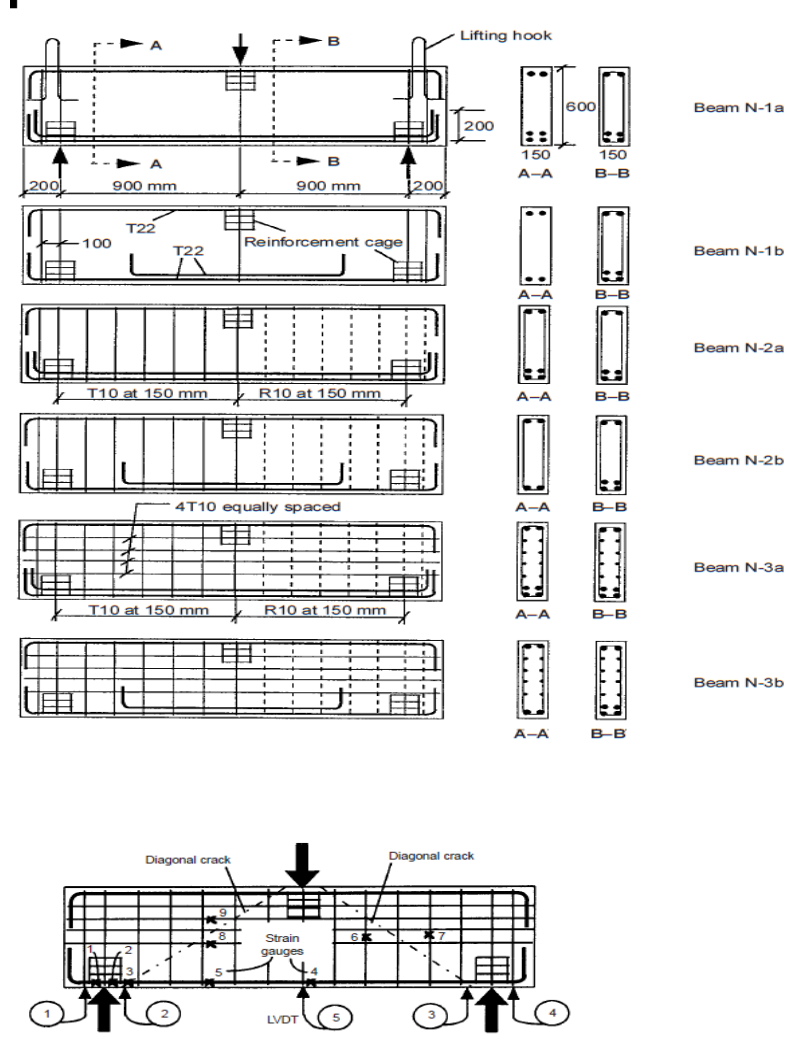

Figure (5), details and test setup of tested specimens used in verification study (Teng et al., 1998).

\subsection{Effect of dilation angle $(\psi)$}

To calibrate the effect of the dilation angle, several analyses are conducted assuming different values of dilation angle varying from 25 to 45 degrees. Figure (7) shows the effect of the dilation angle $(\psi)$ on the load-deflection response of beam N-3b. Beam with a dilation angle of 36 degrees showed the best behavior compared with experimental results. For beams with relatively lower confinement levels (N1-a\& N1-b), Dilation angle of 25 degrees showed a better correlation with experimental results.

\subsection{Effect of viscosity parameter}

To study the effect of the viscosity parameter, multiple analyses are conducted assuming variable values for the viscosity parameter varying from 0 to 0.01 . For the case of the viscosity parameter equal to 0 , the analysis faced conversions problems and didn't proceed beyond the stage of concrete cracking. As shown in figure (8), the closest load-deflection curve to the experimental one is when the viscosity parameter assumed to be 0.01 . Adopting viscosity parameter values lower than 0.01 led to lower ultimate capacity compared to experimental results. 


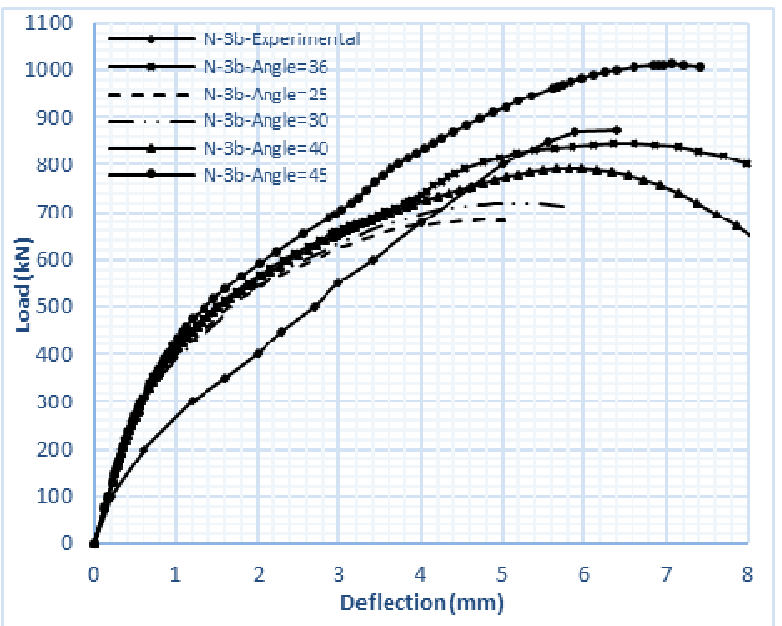

Figure (7), effect of dilation angle ( $\psi$ ) on load deflection response of beam $\mathrm{N}-3 \mathrm{~b}$

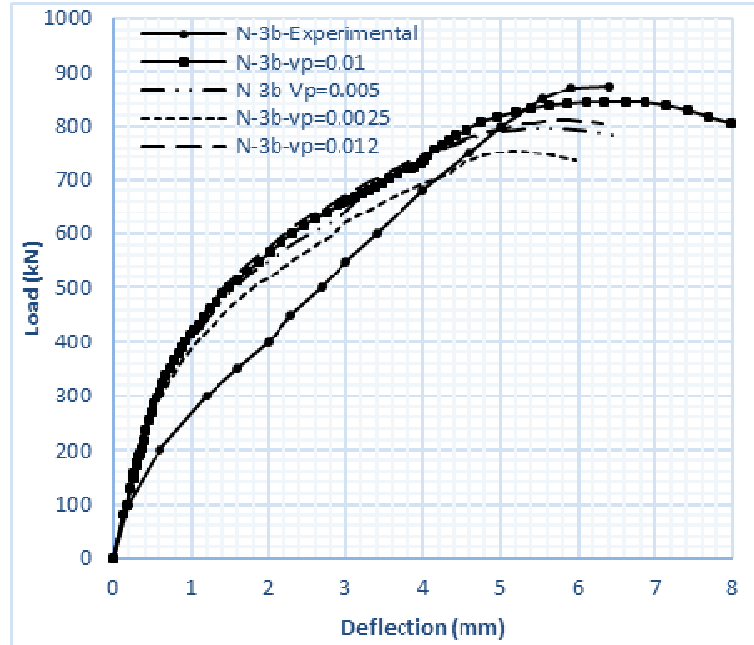

Figure (8), effect of viscosity parameter on load deflection response of beam $\mathrm{N}-3 \mathrm{~b}$

\section{LOAD DEFLECTION BEHAVIOR}

Figure (9) shows a comparison between experimental load-deflection relationships and those obtained by the finite element model. The non-linear finite element model predicted the ultimate capacity of the tested beams with high accuracy. The variation between the experimental and analytical ultimate loads was about $2 \%$. Except for specimens $(\mathrm{N}-2 \mathrm{~b} \& \mathrm{~N}-3 \mathrm{a})$, the variation was 5 , and $4 \%$, respectively. Table (2) summarizes the results of cracking and ultimate loads obtained by the finite element model compared to experimental results.

In addition, the finite element model showed almost identical initial stiffness for the tested specimens compared to experimental results.

Table (2), summary of the FEM results

\begin{tabular}{|c|c|c|c|c|c|c|c|c|}
\hline $\begin{array}{c}\text { Beam } \\
\text { no }\end{array}$ & ID & $\begin{array}{c}\left(\mathrm{P}_{\mathrm{u}}\right)_{\text {exp }} \\
(\mathrm{kN})\end{array}$ & $\begin{array}{c}\left(\mathrm{P}_{\mathrm{u}}\right)_{\mathrm{FE}} \\
(\mathrm{kN})\end{array}$ & $\left(\mathrm{P}_{\mathrm{u}}\right)_{\text {exp }} /\left(\mathrm{P}_{\mathrm{u}}\right)_{\mathrm{FE}}$ & \multicolumn{2}{|c|}{$\begin{array}{c}\text { Experimental Cracking } \\
\text { load }(\mathrm{kN})\end{array}$} & \multicolumn{2}{|c|}{$\begin{array}{c}\text { Model Cracking load } \\
(\mathrm{kN})\end{array}$} \\
\cline { 6 - 9 } & & & & & Flexural & Diagonal & Flexural & Diagonal \\
\hline 1 & $\mathrm{~N}-1 \mathrm{a}$ & 375 & 367.10 & 1.02 & 90 & 225 & 127 & 152 \\
\hline 2 & $\mathrm{~N}-1 \mathrm{~b}$ & 410 & 404.13 & 1.01 & 100 & 200 & 148 & 208 \\
\hline 3 & $\mathrm{~N}-2 \mathrm{a}$ & 875 & 890.23 & 1.02 & 120 & 225 & 159 & 254 \\
\hline 4 & $\mathrm{~N}-2 \mathrm{~b}$ & 775 & 759.21 & 0.95 & 100 & 175 & 156 & 236 \\
\hline 5 & $\mathrm{~N}-3 \mathrm{a}$ & 835 & 844.22 & 0.99 & 150 & 350 & 202 & 262 \\
\hline 6 & $\mathrm{~N}-3 \mathrm{~b}$ & 875 & 866.93 & 0.96 & 100 & 300 & 202 & 254 \\
\hline
\end{tabular}


NON-LINEAR FINITE ELEMENT MODEL FOR REINFORCED CONCRETE DEEP BEAMS FAILING IN SHEAR

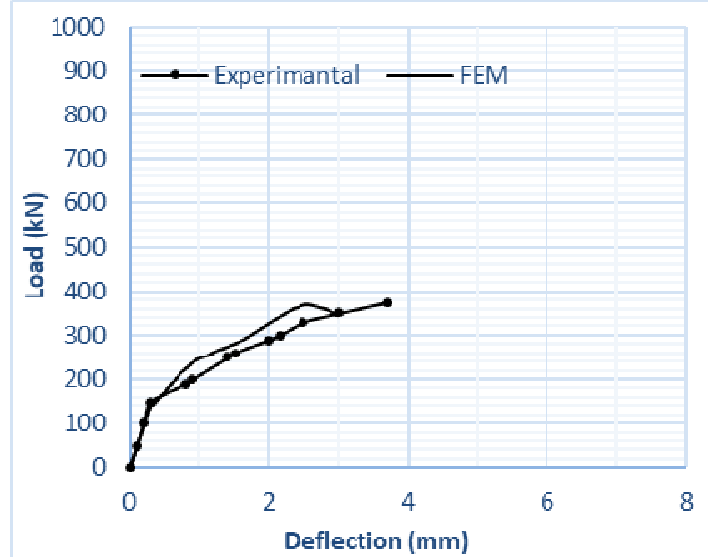

a. Load-deflection relationship for specimen $\mathbf{N}-1$ a

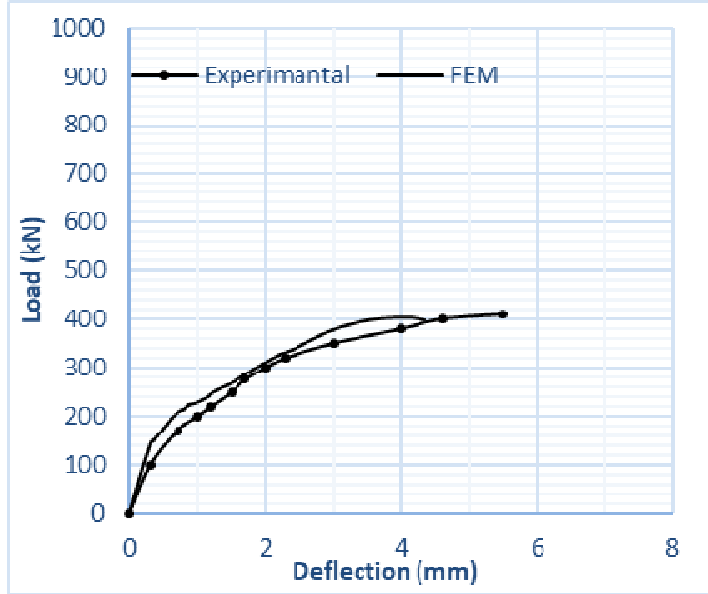

b. Load-deflection relationship for specimen $\mathrm{N}-1 \mathrm{~b}$

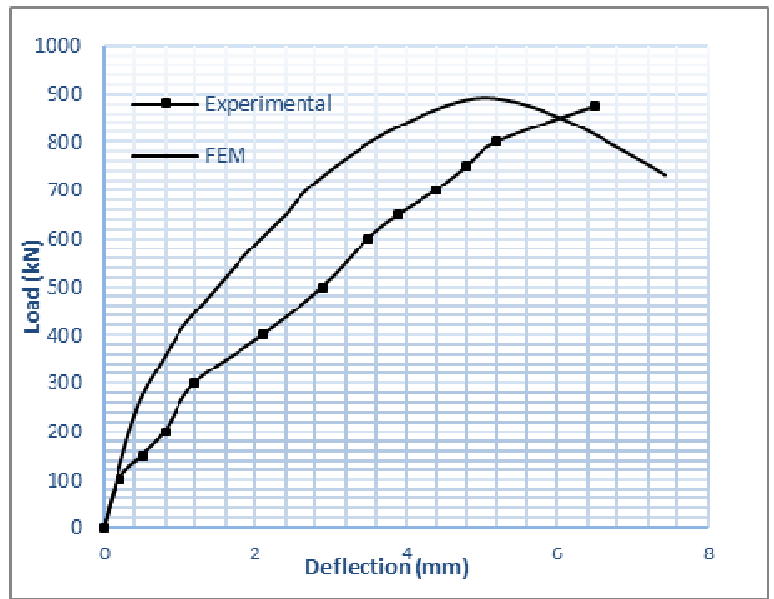

d. Load-deflection relationship for specimen N-2a

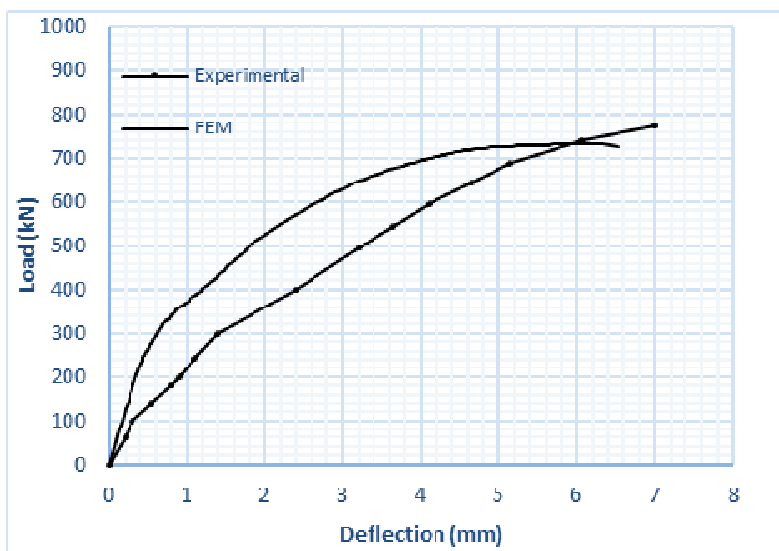

d. Load-deflection relationship for specimen $\mathrm{N}-2 \mathrm{~b}$

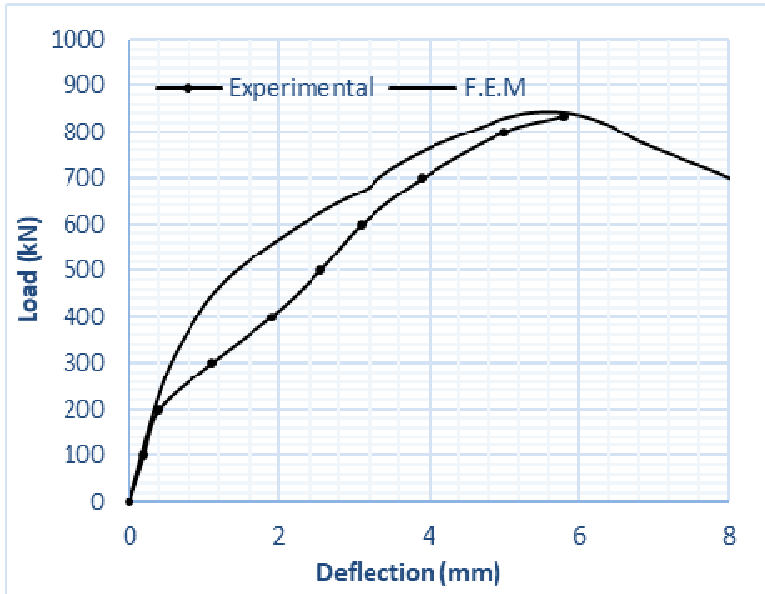

c. e. Load-deflection relationship for specimen $\mathbf{N}-3$ a

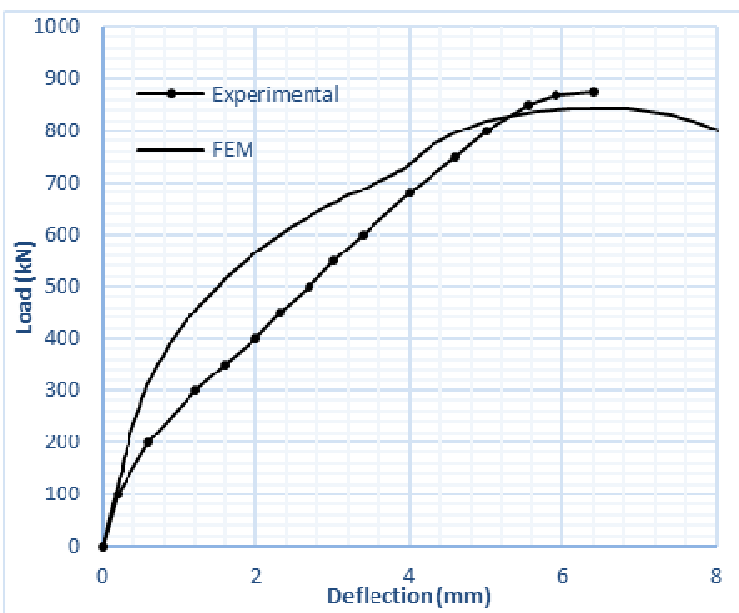

e. f. Load-deflection relationship for specimen $\mathrm{N}-3 \mathrm{~b}$

Figure (9), experimental vs FEM load deflection curves 
Experimental (Teng et al., 1998)

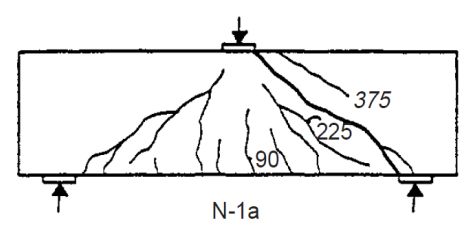

N-1a

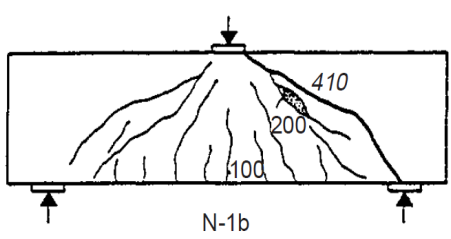

$\mathrm{N}-1 \mathrm{~b}$
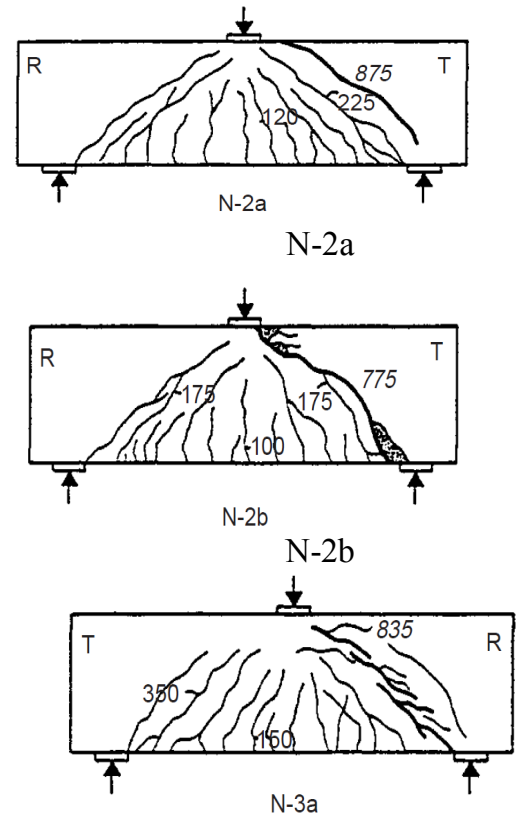

$\mathrm{N}-3 \mathrm{a}$

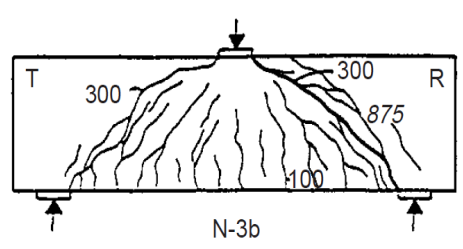

$\mathrm{N}-3 \mathrm{~b}$

\section{Finite element model}
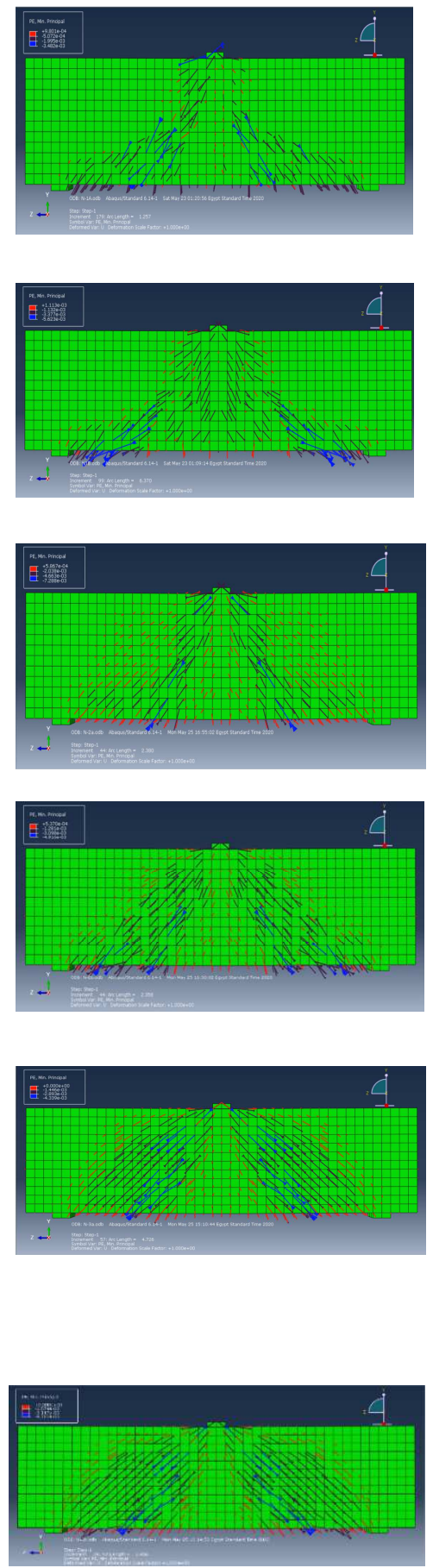

Figure (10), cracks at failure loads for finite element model and experimental beams. 


\section{FLEXURAL AND DIAGONAL CRACKS}

Using the model output of concrete plastic strain, concrete cracks orientations can be presented. Under loading, the first crack for each of the analyzed beams was the flexural crack in the region of the maximum bending moment. For the FEM analyzed beams, this crack initiated at about 23 to $38 \%$ of the ultimate load, depending on beam configuration. With the load increase, more flexural cracks formed. With further load increase, diagonal cracks formed, the increase of the diagonal cracks led to shear failure. The formation of diagonal cracks started at a load level of 30 to $40 \%$ of the ultimate load, depending on the beam's transverse and side reinforcement.

Compared to experimental results, the finite element model showed higher values for flexural and diagonal cracking loads, especially for beams with flexural reinforcement only $(\mathrm{N}-1 \mathrm{a} \& \mathrm{~N}-1 \mathrm{~b})$.

Experimental observations indicated that the first crack was a flexural crack, formed in the region of the maximum bending moment (Teng et al., 1998) The first crack load varied from $11 \%$ of the ultimate load (specimen N-3b) to about $24 \%$ of the ultimate load (specimen N-1a). The results of the finite element model indicated higher cracking loads compared to experimental observations. The cracking loads are varying from $23 \%$ of the ultimate load (specimen N-3b) to $38 \%$ for specimen N-1a. However, the failure mode obtained by the finite element model was the same as the experimental results (diagonal splitting). Figure (10) shows the cracks at failure loads for the finite element model and experimental beams.

\section{CONCLUSIONS}

Using ABAQUS software, the study presented the modeling of RC deep beams subjected to shear failure. The proposed model adopted the concrete damaged plasticity model for concrete. Also, the model was calibrated and compared against experimental results of six beams tested earlier by (Teng et al., 1998). An in-depth investigation was performed to identify the best CDP damage parameters representing the experimental behavior. The recommended viscosity parameter and dilation angle for the analyzed beams turned out to be 0.01 , and $36^{\circ}$ respectively. The comparison showed a close agreement between experimental and FEM results in terms of load-deflection response, crack pattern, and failure mode. Moreover, the best mesh size to apply was $25 \mathrm{~mm}$., adopting course mesh led to unrealistic results, while adopting finer mesh did not enhance the solution accuracy, but increased the problem size.

\section{REFERENCES}

1. Abaqus. (2014). Analysis User's Guide: Volume III: Materials. ABAQUS 6.14 Analysis User's Guide.

2. Carreira, D. J., \& Chu, K. H. (1985). STRESS-STRAIN RELATIONSHIP FOR PLAIN CONCRETE IN COMPRESSION. Journal of the American Concrete Institute. https://doi.org/10.14359/10390

3. Hibbitt, H., Karlsson, B., \& Sorensen, P. (2012). ABAQUS: Theory Manual, version 6.12. In Hks.

4. Lee, J., \& Fenves, G. L. (1998). Plastic-damage model for cyclic loading of concrete structures. Journal of Engineering Mechanics. https://doi.org/10.1061/(ASCE)07339399(1998)124:8(892)

5. Lubliner, J., Oliver, J., Oller, S., \& Oñate, E. (1989). A plastic-damage model for concrete. International Journal of Solids and Structures. https://doi.org/10.1016/00207683(89)90050-4

6. Michat, S., \& Andrzej, W. (2015). Calibration of the CDP model parameters in Abaqus. Advances in Structural Engineering and Mechanics.

7. Śledziewski, K. (2017). Selection of appropriate concrete model in numerical calculation. ITM Web of Conferences. https://doi.org/10.1051/itmconf/20171507012

8. Teng, S., Kong, F. K., \& Poh, S. P. (1998). Shear strength of reinforced and prestressed concrete deep beams. Part II: The supporting evidence. Proceedings of the Institution of Civil Engineers: Structures and Buildings. https://doi.org/10.1680/istbu.1998.30120 